\title{
BODY COMPOSITION, PHYSICAL FITNESS AND PHYSICAL ACTIVITY AMONG STUDENTS FROM UNIVERSITIES IN BIALA PODLASKA
}

\author{
HELENA POPŁAWSKAㄹ, AGNIESZKA DMITRUK1, WOJCIECH HOŁUB² \\ Józef Pitsudski University of Physical Education in Warsaw, Faculty of Physical Education and Health, \\ Department of Health Promotion ${ }^{1}$, Department of Cosmetology ${ }^{2}$, Biała Podlaska, Poland \\ Mailing address: Helena Popławska, Jozef Pilsudski University of Physical Education in Warsaw, \\ Faculty of Physical Education and Health, 2 Akademicka Street, 21-500 Biała Podlaska, tel.: +48 83 3428738, \\ e-mail: helena.poplawska@awf-bp.edu.pl
}

\begin{abstract}
Introduction. Body composition as well as physical fitness and physical activity are determined by a variety of factors affecting an individual, a social group or population. Material and methods. The research included $1^{\text {st }}$ - and $2^{\text {nd }}$-year students from universities located in Biala Podlaska (University of Physical Education - UPE and State School of Higher Education - SSHE). Students were divided into 3 groups. The first group included physical education (PE) students from the UPE, the second group consisted of physiotherapy students from the UPE, while the third group included students from the SSHE. In general, 1107 individuals were examined, including 563 females and 544 males. Body height, body mass, waist circumference, hip circumference and six skinfolds were measured, fat tissue distribution indices such as WHR, TSS, ESS, TER were calculated and body composition was assessed with the use of IOI 353 body composition analyser. Physical activity was assessed using the International Physical Activity Questionnaire (IPAQ). Physical fitness was evaluated by performing EUROFIT tests. Statistical analysis was made on the basis of Shapiro-Wilk and Kruskal-Wallis tests. Results. PE students manifested the highest values of body height, muscle mass and lean body mass as well as the highest level of physical activity and physical fitness. Physiotherapy students had the highest body mass and the highest level of body fat. Students from the SSHE were characterised by the lowest body height and weight, muscle mass and lean body mass. They also manifested the lowest level of total body water. Participants from this university achieved the lowest results in such physical fitness tests as standing broad jump, $10 \times 5 \mathrm{~m}$ shuttle run and sit-andreach. Females from the SSHE also manifested the lowest level of total physical activity. Conclusion. It was concluded that somatic build, physical fitness and physical activity of the participants differ depending on their field of study.
\end{abstract}

Key words: somatic features, motor abilities, physical activity, students

\section{Introduction}

University students constitute one of the most important social groups in every country. In this period of life, dietary habits and health attitudes which make it possible to function in adult life are shaped [1]. Physical fitness of individuals from this age group has nearly all features of motor abilities of an adult and at the same time, the performed movements adapt to activities connected with future work and participation in various forms of physical recreation $[2,3]$.

Different types of studies pose a particular challenge to students. Physical education (PE) students should manifest a high level of physical fitness and somatic build adapted to the selected field of study. Young people from universities of physical education are perceived as a group after two-level selection from the general population. The first selection is connected with their decision to study at the university. Secondly, their physical fitness should be at a higher level than among their counterparts from other fields of study. Several authors have conducted research on long-term tendencies regarding changes in physical development and in the level of physical fitness among PE students. It was revealed that there still occur secular changes towards high stature and slimness of the body in the next generations, while the results regarding physical fitness levels are not unanimous $[4,5,6,7]$. According to the study curriculum objectives, physiotherapy students should also manifest higher levels of physical activity and physical fitness compared to other fields of study. Individuals studying physiotherapy must be prepared for applying physical activity as a means of prevention and treatment in their future job $[8,9]$.

Taking into account the above observations, the aim of the study was to assess body composition, indices of fat tissue distribution as well as physical fitness and physical activity among $\mathrm{PE}$ and physiotherapy students compared to students of other fields of study.

\section{Material and methods}

The research was carried out in 2018 at the Faculty of Physical Education and Health in Biala Podlaska, which is part of the University of Physical Education in Warsaw (UPE) and at the State School of Higher Education in Biala Podlaska (SSHE). The

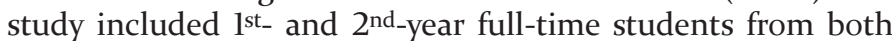
universities. In total, 1107 individuals were examined, including 563 females and 544 males (Tab. 1).

The participants were divided into 3 groups. The first group included physical education (PE) students from the UPE, the second group consisted of physiotherapy students from the 
Table 1. The number of the examined students in groups selected with regard to the field of study

\begin{tabular}{|c|c|c|c|}
\hline Gender & PE & P & SSHE \\
\hline Female & 137 & 67 & 359 \\
\hline Male & 299 & 52 & 193 \\
\hline
\end{tabular}

Key: PE - Physical Education, P - Physiotherapy, SSHE - State School of Higher Education.

UPE, while the third group included students from the SSHE studying economics, management, nursing, dietetics, pedagogy, information technology, finance and accounting.

Anthropological examinations included, inter alia, the measurement of body height and mass, waist and hips circumference and six skinfolds (biceps, triceps, subscapular, suprailiac, abdominal and thigh). Taking into account the values of anthropological measurements, the following indices of fat tissue distribution in students' bodies were calculated: TSS (the sum of three trunk skinfolds), ESS (the sum of three extremity skinfolds) and TER which is calculated as a ratio of TSS to ESS.

Body composition was assessed by means of biological impedance analysis (BIA) with the use of IOI 353 body composition analyser with JAWON MEDICAL software. It made it possible to determine the value of fat tissue (in $\mathrm{kg}$ and \%), lean body (in $\mathrm{kg}$ ), muscle mass (in $\mathrm{kg}$ ), bone tissue mass (w kg), total body water (w \%) and visceral fat (in points).

Physical fitness was assessed on the basis of EUROFIT test battery [10] without endurance shuttle run (due to the fact that PE classes at the SSHE were organised in a room that was not appropriate for performing this test).

Physical activity of the participants was evaluated with the use of the International Physical Activity Questionnaire (IPAQ - short form) [11]. This questionnaire includes 7 questions regarding all types of physical activity in everyday life, during work and rest. Each type of physical activity (vigorous, moderate, walking) is expressed in METs - min/week by multiplying the coefficient representing a particular activity by the number of days of performing it in a week and its duration in minutes per day. Moreover, total activity was calculated according to the IPAQ methodology [11].

Arithmetic means and standard deviations of somatic features and motor tests were calculated for females and males in the selected groups. Normal distribution of quantitative variables was determined with Shapiro-Wilk test. Differences in the obtained results were determined with the use of Kruskal-Wallis test. Calculations were made using Statistica 13.3 software. The research was conducted within the programme of statutory research DS.284.

\section{Results}

The values of somatic features of students from different groups are presented in Table 2 . The data show that females and males studying PE manifested the highest values of body height, and statistically significant differences occurred only between PE students and students from the SSHE. Male PE students also had the highest values of waist circumference. The highest body mass was noted in females and males studying physiotherapy but differences with regard to the remaining fields of study were not statistically significant.

While analysing differences regarding the indices of fat tissue distribution, it was revealed that TSS and ESS values were at the highest level in female physiotherapy students, while in the case of males, the highest values of TSS occurred in the students from the SSHE and the highest values of ESS were found in physiotherapy students. No significant differences regarding the values of TER indicator were found between the selected groups (Tab. 3).

Body composition of the examined students determined with the use of bioelectric impedance varied. Fat tissue, expressed both in kilograms and in percentage values, reached the highest levels in females and males studying physiotherapy. The highest levels of lean body mass, bone tissue mass and total body water were noted in PE students and statistically significant differences were found between PE students and students from the SSHE (Tab. 4).

Table 2. Values of somatic features of the examined students in groups selected with regard to the field of study

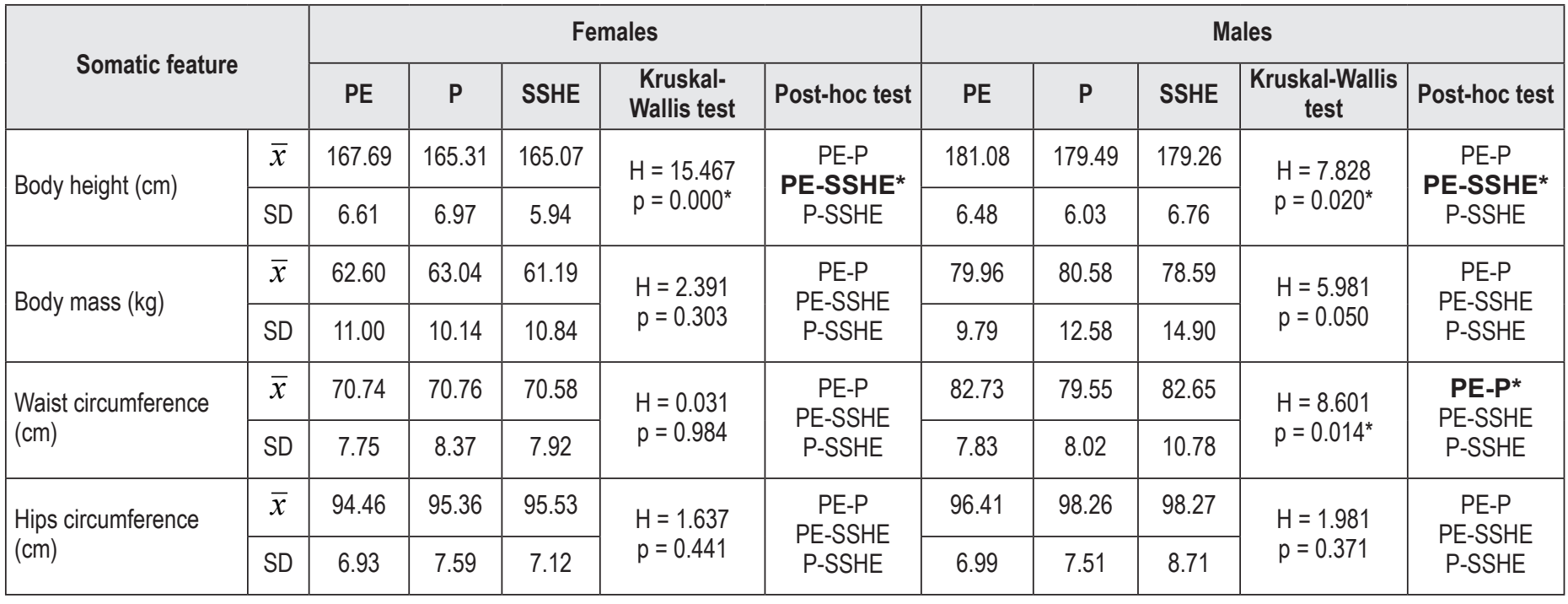

* - statistical significance at the level of $\mathrm{p}<0.05$. 
Table 3. Indicators of fat tissue distribution in the examined students depending on the field of study

\begin{tabular}{|c|c|c|c|c|c|c|c|c|c|c|c|}
\hline \multirow{2}{*}{\multicolumn{2}{|c|}{ Indicator }} & \multicolumn{5}{|c|}{ Females } & \multicolumn{5}{|c|}{ Males } \\
\hline & & \multirow{2}{*}{$\begin{array}{c}\text { PE } \\
46.48\end{array}$} & \multirow{2}{*}{$\begin{array}{c}\mathbf{P} \\
51.49\end{array}$} & \multirow{2}{*}{$\begin{array}{r}\text { SSHE } \\
49.16\end{array}$} & \multirow{3}{*}{$\begin{array}{c}\begin{array}{c}\text { Kruskal-Wallis } \\
\text { test }\end{array} \\
H=3.175 \\
p=0.204\end{array}$} & \multirow{3}{*}{$\begin{array}{c}\text { Post-hoc test } \\
\text { PE-P } \\
\text { PE-SSHE } \\
\text { P-SSHE }\end{array}$} & \multirow{2}{*}{$\begin{array}{c}\text { PE } \\
40.26\end{array}$} & \multirow{2}{*}{$\begin{array}{c}\mathbf{P} \\
45.76\end{array}$} & \multirow{2}{*}{$\begin{array}{l}\text { SSHE } \\
47.56\end{array}$} & \multirow{3}{*}{$\begin{array}{c}\begin{array}{c}\text { Kruskal-Wallis } \\
\text { test }\end{array} \\
H=7.212 \\
p=0.027^{*}\end{array}$} & \multirow{3}{*}{$\begin{array}{c}\text { Post-hoc tes } \\
\text { PE-P } \\
\text { PE-SSHE } \\
\text { P-SSHE }\end{array}$} \\
\hline \multirow{2}{*}{ TSS } & $\bar{x}$ & & & & & & & & & & \\
\hline & SD & 17.60 & 20.46 & 19.01 & & & 15.60 & 17.40 & 24.11 & & \\
\hline \multirow{2}{*}{ ESS } & $\bar{x}$ & 39.59 & 41.45 & 39.32 & \multirow{2}{*}{$\begin{array}{l}H=5.438 \\
p=0.066\end{array}$} & \multirow{2}{*}{$\begin{array}{c}\text { PE-P } \\
\text { PE-SSHE } \\
\text { P-SSHE }\end{array}$} & 25.30 & 29.40 & 28.09 & \multirow{2}{*}{$\begin{array}{l}H=10.924 \\
p=0.004^{*}\end{array}$} & \multirow{2}{*}{$\begin{array}{c}\text { PE-P* } \\
\text { PE-SSHE* } \\
\text { P-SSHE }\end{array}$} \\
\hline & SD & 14.83 & 9.51 & 10.71 & & & 9.10 & 10.31 & 10.95 & & \\
\hline \multirow{2}{*}{ TER } & $\bar{x}$ & 1.22 & 1.23 & 1.24 & \multirow{2}{*}{$\begin{array}{l}H=0.871 \\
p=0.647\end{array}$} & \multirow{2}{*}{$\begin{array}{c}\text { PE-P } \\
\text { PE-SSHE } \\
\text { P-SSHE }\end{array}$} & 1.65 & 1.57 & 1.70 & \multirow{2}{*}{$\begin{array}{l}H=0.725 \\
p=0.696\end{array}$} & \multirow{2}{*}{$\begin{array}{c}\text { PE-P } \\
\text { PE-SSHE } \\
\text { P-SSHE }\end{array}$} \\
\hline & SD & 0.37 & 0.34 & 0.29 & & & 0.54 & 0.35 & 0.58 & & \\
\hline
\end{tabular}

* - statistical significance at the level of $\mathrm{p}<0.05$.

Table 4. Body composition of the examined students in groups selected with regard to the field of study

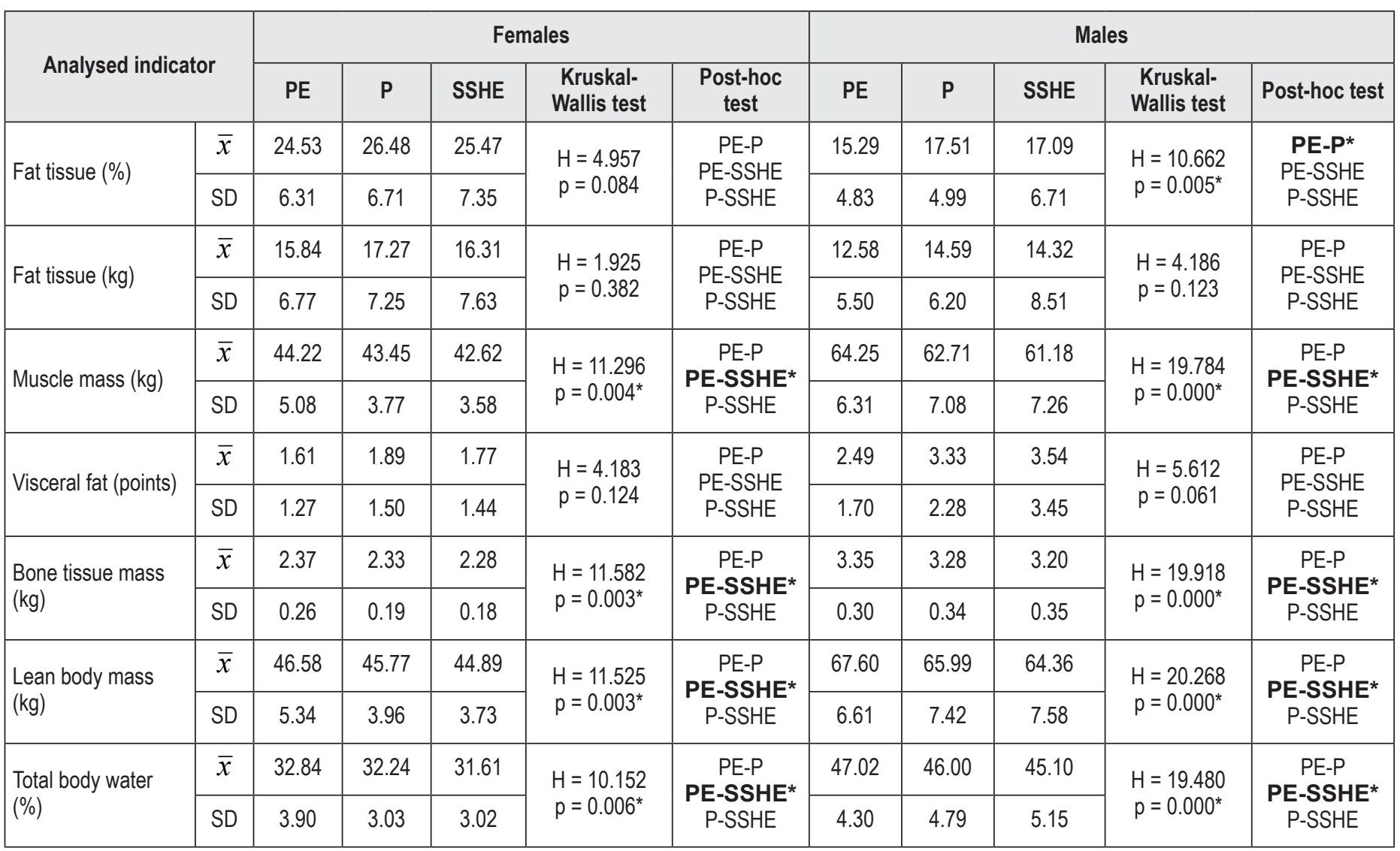

* - statistical significance at the level of $\mathrm{p}<0.05$.

Females and males studying PE manifested the highest levels of total physical activity. The lowest values of total physical activity were observed in females studying at the SSHE and in male physiotherapy students. Kruskal-Wallis test revealed that both in females and in males, there were statistically significant differences between the participants from the UPE and those from the SSHE. Similar differences in the results occurred in the case of vigorous physical activity. However, in males, statistically significant differences were noted between the participants studying PE and students from the SSHE and between PE and physiotherapy students, while in females, between PE students and those studying at the SSHE. Moderate physical activity was at the highest level among females studying physiotherapy and among males studying at the SSHE. In males, the obtained differences were not statistically significant, while in females, the significance of differences was noted between PE students and SSHE students. The largest amount of walking per week was noted among female PE students and male students from the SSHE. The obtained differences were not statistically significant (Tab. 5 and 6). 
Table 5. The level of physical activity of the examined female students depending on their field of study

\begin{tabular}{|c|c|c|c|c|c|c|}
\hline \multirow{2}{*}{\multicolumn{2}{|c|}{ Type of activity }} & \multicolumn{5}{|c|}{ Females } \\
\hline & & PE & $\mathbf{P}$ & SSHE & Kruskal-Wallis test & Post-hoc test \\
\hline \multirow{2}{*}{ Vigorous activity (MET-min./week) } & $\bar{x}$ & 2404.38 & 1360.00 & 1173.90 & \multirow{2}{*}{$\begin{array}{l}H=18.534 \\
P=0.000^{*}\end{array}$} & \multirow{2}{*}{$\begin{array}{c}\text { PE-P } \\
\text { PE-SSHE* } \\
\text { P-SSHE }\end{array}$} \\
\hline & SD & 2674.47 & 1421.15 & 1426.68 & & \\
\hline \multirow{2}{*}{ Moderate activity (MET-min./week) } & $\bar{x}$ & 1207.09 & 1219.13 & 668.98 & \multirow{2}{*}{$\begin{array}{l}H=23.039 \\
P=0.000^{*}\end{array}$} & \multirow{2}{*}{$\begin{array}{c}\text { PE-P } \\
\text { PE-SSHE* } \\
\text { P-SSHE }\end{array}$} \\
\hline & SD & 1499.59 & 2057.78 & 864.88 & & \\
\hline \multirow{2}{*}{ Walking (MET-min./week) } & $\bar{x}$ & 1649.59 & 1421.06 & 1343.27 & \multirow{2}{*}{$\begin{array}{l}H=7.488 \\
P=0.024^{*}\end{array}$} & \multirow{2}{*}{$\begin{array}{c}\text { PE-P } \\
\text { PE-SSHE } \\
\text { P-SSHE }\end{array}$} \\
\hline & SD & 2231.68 & 1068.33 & 1891.15 & & \\
\hline \multirow{2}{*}{ Total activity (MET-min./week) } & $\bar{x}$ & 5018.23 & 3239.48 & 2482.87 & \multirow{2}{*}{$\begin{array}{l}H=45.323 \\
P=0.000^{*}\end{array}$} & \multirow{2}{*}{$\begin{array}{c}\text { PE-P } \\
\text { PE-SSHE* } \\
\text { P-SSHE }\end{array}$} \\
\hline & SD & 4358.65 & 3206.24 & 3022.99 & & \\
\hline
\end{tabular}

* - statistical significance at the level of $\mathrm{p}<0.05$.

Table 6. The level of physical activity of the examined male students depending on their field of study

\begin{tabular}{|c|c|c|c|c|c|c|}
\hline \multirow{2}{*}{\multicolumn{2}{|c|}{ Type of activity }} & \multicolumn{5}{|c|}{ Males } \\
\hline & & PE & $\mathbf{P}$ & SSHE & Kruskal-Wallis test & Post-hoc test \\
\hline \multirow{2}{*}{ Vigorous activity (MET-min./week) } & $\bar{x}$ & 3702.49 & 2371.29 & 2821.85 & \multirow{2}{*}{$\begin{array}{l}H=16.936 \\
p=0.000^{*}\end{array}$} & \multirow{2}{*}{$\begin{array}{l}\text { PE-P* } \\
\text { PE-SSHE* } \\
\text { P-SSHE }\end{array}$} \\
\hline & SD & 4222.00 & 3629.01 & 4335.56 & & \\
\hline \multirow{2}{*}{ Moderate activity (MET-min./week) } & $\bar{x}$ & 1379.69 & 1391.25 & 1525.45 & \multirow{2}{*}{$\begin{array}{l}H=4.782 \\
p=0.092\end{array}$} & \multirow{2}{*}{$\begin{array}{c}\text { PE-P } \\
\text { PE-SSHE } \\
\text { P-SSHE }\end{array}$} \\
\hline & SD & 1323.47 & 2202.77 & 2313.26 & & \\
\hline \multirow{2}{*}{ Walking (MET-min./week) } & $\bar{x}$ & 1635.88 & 1429.31 & 1765.41 & \multirow{2}{*}{$\begin{array}{l}H=0.309 \\
p=0.857\end{array}$} & \multirow{2}{*}{$\begin{array}{c}\text { PE-P } \\
\text { PE-SSHE } \\
\text { P-SSHE }\end{array}$} \\
\hline & SD & 2206.39 & 1639.48 & 2531.03 & & \\
\hline \multirow{2}{*}{ Total activity (MET-min./week) } & $\bar{x}$ & 6316.93 & 4496.89 & 5177.77 & \multirow{2}{*}{$\begin{array}{l}H=14.356 \\
p=0.001^{*}\end{array}$} & \multirow{2}{*}{$\begin{array}{c}\text { PE-P } \\
\text { PE-SSHE* } \\
\text { P-SSHE }\end{array}$} \\
\hline & SD & 6288.24 & 5574.81 & 7474.88 & & \\
\hline
\end{tabular}

* - statistical significance at the level of $\mathrm{p}<0.05$.

A similar tendency regarding differences in the results was noted as far as physical fitness is concerned. The best results in all the analysed fitness tests were achieved by the participants studying PE except for sit-and-reach test performed by females, where physiotherapy students achieved the highest values. The lowest level of physical fitness was noted in the participants from the SSHE except for handgrip strength, bent arm hang and sit-ups in females as well as handgrip strength, bent arm hang and flamingo balance in males. In these tests, the lowest results were achieved by physiotherapy students. Statistical significance of differences between the results of all fitness tests, except for handgrip strength in males, was noted between PE students and the participants from the SSHE. Differences between physiotherapy students and students from the SSHE were statistically significant less frequently (Tab. 7).

\section{Discussion}

Physical activity plays a significant role in promoting health and well-being. It differs depending on age, gender, state of health and type of work. PE students constitute a group that should undoubtedly express a higher interest in physical activity. This thesis is confirmed by the results of the authors' own study that revealed a higher level of physical activity among PE students than among students of other fields of study. The mean total physical activity among female PE students was at the level of 5018.23 MET-min/week and was higher by 1778.75 METmin/week than among female physiotherapy students and by 2535.36 MET-min/week than among students from the SSHE. In males, larger differences regarding total physical activity, i.e. 1820.04 MET-min/week, were noted compared to physiothera- 
Table 7. Physical fitness of the examined students depending on their field of study

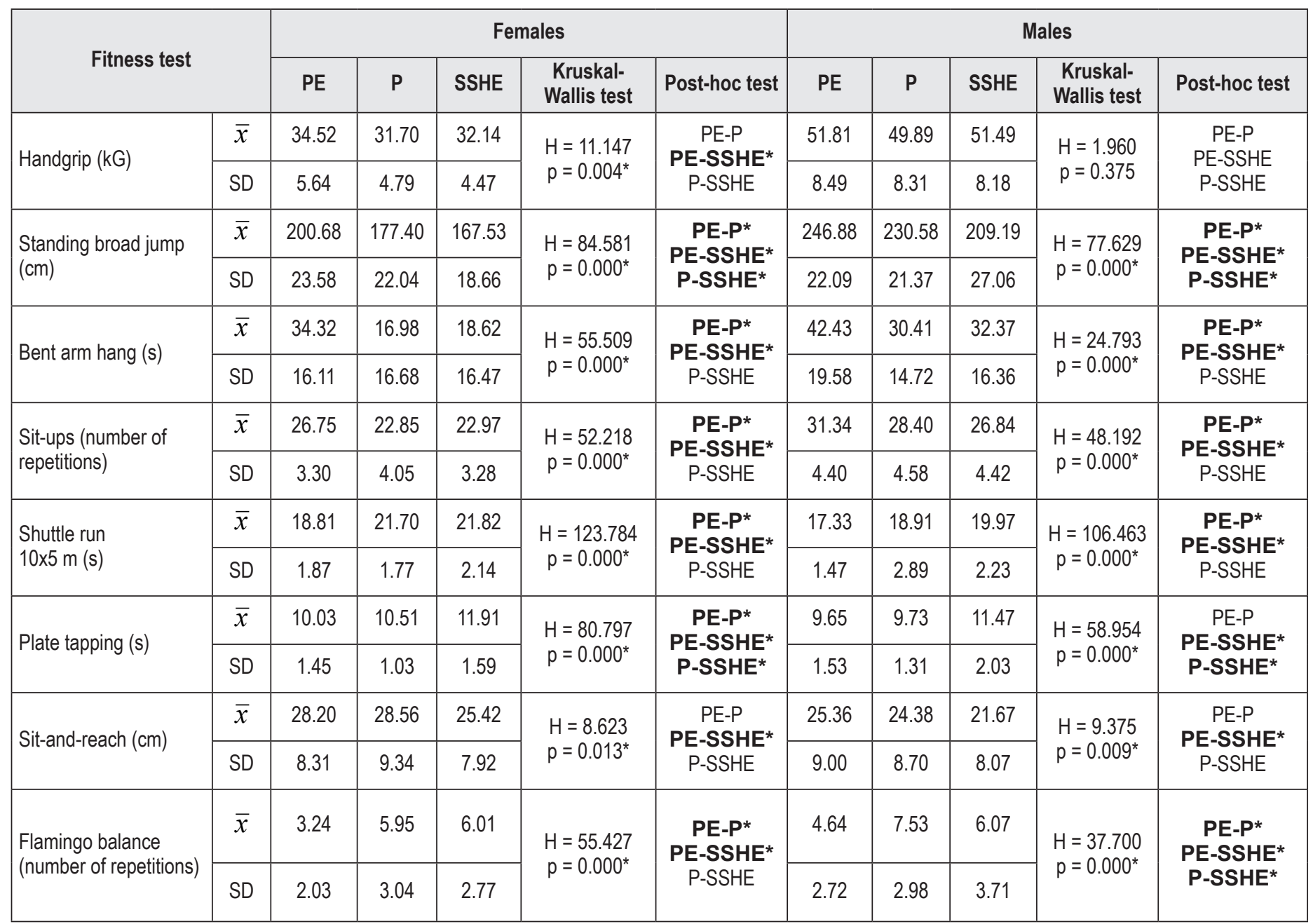

* - statistical significance at the level of $\mathrm{p}<0.05$.

py students, while with regard to students from the SSHE, the difference was at the level of $1139.16 \mathrm{MET}$-min/week.

The research conducted at the universities in Slovakia [12] also confirmed that students of sports-related fields of study manifest a more positive attitude to physical activity than students of other fields of study. This study also revealed that students of teaching-related fields of study prefer pro-health classes devoted to body shaping, while students of sports-related fields of study choose exercises that focus on boosting performance.

The comparison of total physical activity between students from Biala Podlaska and Tourism and Recreation students from the University of Physical Education in Cracow revealed that the results of both groups differed only to a slight extent [13]. Males from the UPE in Cracow achieved a mean value of total physical activity at the level of 6308 MET-min/week (compared to our own research, the difference is at the level of 8.93 METmin/week), while females - 5599 MET-min/week (difference of 580.77 MET-min/week in favour of the participants from the UPE in Cracow). While comparing physical activity of Polish and Turkish students, Bednarek et al. [13] revealed that Turkish students of Tourism and Recreation manifested a lower level of total and vigorous physical activity compared to Polish students and the majority (60\%) did not meet the guidelines of the World Health Organisation on the minimal level of physical activity required to maintain health.

The study assessing physical activity of students with the use of the IPAQ was also conducted in other fields of study. While evaluating physical activity of students from the University in Tuzla (Bosnia and Herzegovina), Mulahasanović et al. [14] reported that their mean total physical activity was at the level of 6013.39 MET-min/week, while female students achieved a lower level of total physical activity, i.e. 4619.39 MET-min/week. The results of males were similar to the results of PE students from Biala Podlaska, while the results of females were higher than the results of female students from Biala Podlaska (both physiotherapy students and those studying at the SSHE). The study by Pedišić et al. [15] revealed that total physical activity of students from Croatia (3241.80 MET-min/week in males and 2979 MET-min/week in females) was considerably lower compared to the findings of our own study, both in females and in males, except for females from the SSHE.

A high level of physical activity, particularly a high level maintained for many years, helps to achieve and maintain a high level of physical fitness. Our own research revealed that, apart from manifesting the highest level of physical activity, PE students also demonstrated a high level of physical fitness that 
was higher than that of students of other fields of study. They achieved the best results in all the analysed fitness tests, except for the sit-and-reach test in females, where physiotherapy students achieved the highest results. Similar correlations regarding differences in the level of physical fitness among students of different fields of study were revealed by Januszewski and Mleczko [16]. They assessed the level of physical fitness among students of the UPE and other universities from Cracow. In all the fitness tests, higher results were noted in students from the UPE. Similar results were revealed by Majcher et al. [17] in their research on students from the UPE and the University of Silesia in Katowice. A higher level of physical fitness of students from the UPE is probably connected with the university admission process which accepts candidates who are more interested in physical exercise and are more predisposed to study in this field.

A high level of physical fitness is strongly correlated with body build. In physically fit and active individuals, lean body mass, including muscle mass, should constitute the largest percentage, while excessive fat tissue is perceived as unfavourable [18]. Our own research revealed considerable differences (often statistically significant) between PE students and students of other fields of study as far as body composition is concerned. PE students manifested better, in terms of health, body composition. They had higher values of body height, muscle mass and lean body mass. Females and males from this group had the highest values of bone mass and the highest level of total body water. Physiotherapy students proved to have the highest levels of body fat. Similar results regarding body composition of PE students compared to other fields of study were presented by Čabrićet al. [18] and Resendeet al. [19]. What is alarming in the results of our research is the fact that women and men studying physiotherapy had a high level of body fat. Theoretically, they should present a high level of knowledge about the negative influence of excessive body fat on human health. However, as the findings of our research and studies of other authors [20, 21] show, body composition of students of medical fields of study is often far from accepted norms due to excessive body fat.

To sum up, our own research confirmed the effects of selected factors in the context of the choice of the field of study by PE students. This field of study is usually chosen by physically fit individuals who are interested in participating in various forms of physical activity and whose somatic build makes it possible to do sports.

\section{Conclusions}

1. It was concluded that somatic build, physical activity and physical fitness among the participants differed depending on the field of study.

2. PE students manifested better body composition in terms of health. They had higher values of body height, muscle mass and lean body mass, while physiotherapy students proved to have more fat tissue.

3. The highest levels of total physical activity and physical fitness were noted in PE students. Male and female students from the SSHE achieved the lowest results in the majority of physical fitness tests.

\section{References}

1. Yahia N., Wang D., Rapley M., Dey R. (2016). Assessment of weight status, dietary habits and beliefs, physical activity, and nutritional knowledge among university students. Perspectives in Public Health 136(4), 231-244.
2. López-Sánchez G.F., Radzimiński Ł., Skalska M., Jastrzębska J., Smith L., Wakuluk D. et al. (2019). Body composition, physical fitness, physical activity and nutrition in Polish and Spanish male students of Sports Sciences: differences and correlations. International Journal of Research and Public Health 16(7), E 1148.

3. Kiss K., Mészáros Z., Mavroudes M., Szmodis MB., Zsidegh M., Ng N. et al. (2009). Fitness and nutritional status of female medical university students. Acta Physiologica Hungarica 96(4), 469-474.

4. Mleczko E., Januszewski J. (2009). Długookresowe tendencje przemian w rozwoju somatycznym i motorycznym krakowskich studentów. Kinesiology 46, 65-79.

5. Saczuk J., Wasiluk A., Wilczewski R., Wilczewski A. (2016). Differences in body build and physical fitness of PE students from the Faculty of Physical Education and Sport in Biała Podlaska in the years 1989, 2004, and 2014. Polish Journal of Sport and Tourism 23, 212-220.

6. Saczuk J., Wasiluk A. (2019). Secular trends in the physical fitness of underweight, overweight, and obese girls. Polish Journal of Sport and Tourism 26(1), 28-32.

7. Yagi T., Takebe Y., Itoh M. (1989). Secular trends in physique and physical fitness in Japanese students during the last 20 years. American Journal of Human Biology 1(5), 581-587.

8. Przysada G., Kozicki R., Maślanka M. (2012). Physical activity and physical fitness in physiotherapy students of the University of Rzeszów. Medycyna Sportowa 4(4), 28, 277284.

9. Sochacka L., Wojtyłko A. (2013). Physical activity of full-time students from medical and non-medical fields of study. Environmental Medicine 16(2), 53-58.

10. Eurofit. European Test of Physical Fitness (1988). Rome: Council of Europe, Committee for the Development of Sport.

11. Biernat E., Stupnicki R., Gajewski A. (2007). International Physical Activity Questionnaire (IPAQ) - Polish version. Physical Education and Sport 51 (10), 47-54.

12. Masaryková D., Labudová J., Matuš I. (2016). Physical activity of university students with various study profile. Physical Activity Review 4, 107-114.

13. Bednarek J., Pomykała S., Bigosińska M., Szyguła Z. (2016). Physical activity of Polish and Turkish university students as assessed by IPAQ. Central European Journal of Sport Sciences and Medicine 16(4), 13-22.

14. Mulahasanović I.Ć., Mujanović A.M., Mujanović E., Atiković A. (2018). Level of physical activity of students at the University of Tuzla according to IPAQ. Central European Journal of Sport Sciences and Medicine 21(1), 23-30.

15. Pedišić Ź., Rakovac M., Bennie J., Jurakić D., Bauman A.E. (2014). Levels and correlates of domain-specific physical activity in university students: cross-sectional finding from Croatia. Kinesiology 1(46), 12-22.

16. Januszewski J., Mleczko E. (2007). Evaluation of physical fitness of students from Cracow: theoretical assumptions, practical implications. Antropomotoryka 39, 25-40.

17. Majcher W., Sapeta A., Mynarski W. (2007). Physical fitness of students from the Academy of Physical Education and the University of Silesia in Katowice assessed in terms of health. Zeszyty Metodyczno-Naukowe AWF, Katowice 23, 107-115.

18. Čabrić M., Krakowiak H., Krakowiak A. (2010). Traits of body musculature in students of medicine and physical education. Medical and Biological Sciences 24(1), 19-24.

19. Resende M.A., Resende R.B., Tavares R.S., Santos C.R., Barreto-Filho J.A. (2010). Comparative study of the pro-athero- 
sclerotic profile of students of medicine and physical education. Arquivos Brasileiros de Cardiologia 95(1), 21-29.

20. van den Berg V., Okeyo A., Dannhauser A., Nel M. (2012). Body weight, eating practices and nutritional knowledge among university nursing students, Eastern Cape, South Africa. The African Journal of Primary Health Care E Family Medicine 4(1), 323-332.
21. Lehmann F., von Lindeman K., Klewer J., Kugler J. (2014). BMI, physical inactivity, cigarette and alcohol consumption in female nursing students: a 5-year comparison. BMC Medical Education 14, 82-87.

Submitted: December 3, 2019.

Accepted: March 24, 2020. 